\title{
PERBANDINGAN METODE BACKPROPAGATION DENGAN MONTE CARLO DALAM MEMPREDIKSI JUMLAH PENDERITA DEMAM BERDARAH DENGUE DI KOTA PEKANBARU
}

\author{
${ }^{1)}$ Junadhi, ${ }^{2)}$ Agustin, ${ }^{3)}$ Susanti \\ ${ }^{1,2,3)}$ Teknik Informatika, STMIK Amik Riau \\ 1,2,3) Jl. Purwodadi Indah, km.10 Panam - Pekanbaru \\ E-Mail:junadhi@stmik-amik-riau.ac.id,agustin@stmik-amik-riau.ac.id,susanti@stmik-amik-riau.ac.id
}

\begin{abstract}
ABSTRAK
Kota Pekanbaru merupakan salah satu kota yang memiliki kasus demam berdarah yang cukup tinggi, yaitu tahun 2012 tercatat 202 kasus, 2013426 kasus, 2014 tercatat 113 kasus dan pada tahun 2015 tercatat sebanyak 272 kasus. Jumlah setiap tahunnya selalu berubah-ubah, karena disebabkan berbagai faktor yaitu perubahan cuaca yang tidak menentu dan lainnya, hal tersebut membuktkani bahwa Dinas Kesehatan Kota Pekanbaru belum mampu mengendalikan laju peningkatan penderita demam berdarah. Metode Backpropagation adalah metode peramalan yang sistematik untuk pelatihan multilayer, memiliki dasar matematis yang kuat dan dilatih dengan metode terbimbing.. Dengan 3 lapisan, yaitu lapisan masukan, tersembunyi dan keluaran. Simulasi Monte Carlo adalah tipe simulasi probabilistik dimana untuk memperoleh penyelesaian masalahnya digunakan metode sampling dari proses random. Monte Carlo mengadakan percobaan pada elemen probabilistic melalui sampling acak dengan bantuan pembangkitan bilangan random. Dengan membandingkan kedua tersebut dapat diketahui metode mana yang lebih bagus dalam memprediksi jumlah penderita demam berdarah. Hasil pengujian data dengan kedua metode didapat bahwa metode Backpropagation memiliki standar deviasi yang rendah dibanding metode Monte Carlo, sehingga metode Backpropagation dikatakan lebih baik dalam memprediksi jumlah penderita penyakit demam berdarah dengue di Kota Pekanbaru
\end{abstract}

Kata Kunci: Prediksi, Demam Berdarah Dengue, Backpropagation, Monte Carlo

\begin{abstract}
Pekanbaru city is one of the cities that have high dengue fever cases. in 2012 recorded 202 cases, 2013426 cases, 2014 recorded 113 cases and in 2015 recorded as many as 272 cases. The number of each year is always changing, due to various factors that are erratic and other weather changes, it proves that Departmenet of Health of Pekanbaru City has not been able to control the rate of increase in dengue fever patients. The Backpropagation method is a systematic forecasting method for multilayer training, has a strong mathematical basis and is trained by guided methods. With 3 layers, the input layer, the hidden layer and the output layer. Monte Carlo simulation is a probabilistic type of simulation where to obtain the problem solving used sampling method from random process. Monte Carlo experiments on probabilistic elements through random sampling with the aid of generating random numbers. By comparing the two can be known which method is better in predicting the number of patients with dengue fever. The results of data testing with both methods found that Backpropagation method has a low standard deviation compared to Monte Carlo method, so the method of backpropagation is said to be better in predicting the number of dengue hemorrhagic fever patients in Pekanbaru City
\end{abstract}

Keywords: Prediction, Dengue Hemorrhagic Fever, Backpropagation, Monte Carlo

\section{PENDAHULUAN}

Kota Pekanbaru merupakan salah satu kota yang memiliki kasus demam berdarah yang cukup tinggi, yaitu tahun 2012 tercatat 202 kasus, 2013426 kasus, 2014 tercatat 113 kasus, dan pada tahun 2015 tercatat sebanyak 272 kasus penderita demam berdarah. Jumlah setiap tahunnya selalu berubah-ubah, karena disebabkan berbagai faktor yaitu perubahan cuaca yang tidak menentu dan tidak bersihnya lingkungan, hal tersebut merupakan bukti bahwa Dinas Kesehatan Kota Pekanbaru belum mampu mengendalikan laju pertumbuhan penderita demam berdarah. Oleh karena itu, diperlukan suatu pemecahan masalah agar jumlah penderita penyakit 
demam berdarah di Kota Pekanbaru berkurang. Salah satu solusinya yaitu dengan memprediksi jumlah penderita demam berdarah untuk tahun berikutnya, agar pihak yang berwenang dapat melakukan tindakan yang mampu mengatasi peningkatan jumlah penderita demam berdarah di Kota Pekanbaru. Dalam hal ini, dilakukan perbandingan dua buah metode untuk memprediksi jumlah penderita demam berdarah tersebut.

Metode yang popular dalam bidang peramalan adalah metode Jaringan Saraf Tiruan (JST) dan Metode Monte Carlo. Metode jaringan saraf tiruan dapat diaplikasikan dengan baik untuk melakukan peramalan (forecasting) dan salah satu teknik peramalan yang sering digunakan adalah Backpropagation.

Beberapa peneliti terdahulu telah melakukan penelitian tentang prediksi menggunakan Backpropagation dan Monte Carlo .Penelitian M.F. Andrijasa dan Mistianingsih [1] memprediksi jumlah pengangguran di Provinsi Kalimantan Timur dengan menggunakan metode Backpropagation diperoleh hasil prediksi jumlah pengangguran pada tahun 2009 adalah 133.104. Sedangkan hasil prediksi jumlah pengangguran tahun 2009 yang dilakukan oleh BPS Provinsi Kalimantan Timur adalah 139.830. Kemudian penelitian dari Adnan Fadjar [2] dengan judul aplikasi metode Monte Carlo dalam estimasi biaya proyek dari penelitian ini dihasilkan metode Monte Carlo dapat menjadi alat yang handal bagi manajer proyek dalam menganalisa resiko dan ketidak-pastian yang umum terjadi dalam pembiayaan proyek. Hasil metode Monte Carlo dapat membantu manajer proyek dalam menentukan ekspektasi pembiayaan proyek yang lebih realistis

\section{Rumusan Masalah}

Rumusan masalah yang diangkat dalam penelitian ini adalah bagaimana hasil perbandingan metode Backpropagation dengan metode Monte Carlo dapat digunakan dalam memprediksi jumlah penderita demam berdarah dengue di Kota Pekanbaru.

\section{Batasan Masalah}

Agar penelitian ini lebih terarah, maka dianggap perlu untuk memberikan ruang lingkup penelitian sebagai batasan dari penelitian ini. Adapun ruang lingkup dari penelitian ini adalah:

1. Data yang digunakan adalah data 4 tahun terakhir.

2. Pengujian perbandingan kedua metode menggunakan standar deviasi.

\section{Tujuan}

Adapun tujuan penelitian yang didasari oleh latar belakang masalah dan ruang lingkup penelitian adalah membandingkan metode Backpropagation dengan Monte Carlo dalam memprediksi jumlah penderita Demam Berdarah Dengue di Kota Pekanbaru.

\section{Manfaat}

1. Dapat membantu pihak Dinas Kesehatan Kota Pekanbaru dalam mengendalikan laju pertumbuhan jumlah penderita demam berdarah.

2. Adanya prediksi jumlah penderita untuk tahun berikutnya, dapat membantu pihak yang berwenang untuk melakukan tindakan yang mampu mengatasi peningkatan jumlah penderita demam berdarah di Kota Pekanbaru.

Metode Backpropagation adalah sebuah metode sistematik untuk pelatihan multilayer Jaringan Syaraf Tiruan, yang memiliki dasar 
matematis yang kuat dan dilatih dengan metode terbimbing. Sering digunakan untuk menyelesaikan masalah-masalah rumit. Ada tiga lapis Jaringan Syaraf Tiruan, yaitu lapisan masukan (input layer), lapisan tersembunyi (hidden layer), lapisan keluaran (output layer) (Badrul Anwar, 2011).

Menurut Nurhayati (2010), ada beberapa parameter-parameter yang menentukan keberhasilan suatu proses belajar pada metode Backpropagation:

a. Inisialisasi bobot

Salah satu pilihan yang dapat digunakan adalah memilih nilai bobot pada suatu rentang nilai seperti $-0,5$ dan 0,5.

b. Kecepatan belajar $(\alpha)$

Parameter kecepatan belajar menunjukan intensitas dalam proses belajar, dan menentukan efektivitas dan konvergensi dari pelatihan.

c. Momentum $(\mu)$

Peningkatan kecepatan proses pelatihan dilakukan dengan menambahkan parameter momentum dengan rentang nilai 0 sampai dengan 1 dan nilai optimal adalah 0,9.

d. Kesalahan Belajar dan Batas Iterasi

Tingkat keberhasilan proses belajar dari sebuah jaringan yang sedang dilatih dapat dilihat dari parameter $E$ (error) yang menunjukkan kemampuan jaringan.

Sebelum melakukan pelatihan dengan Backpropagation terlebih dahulu dilakukan transformasi pada data latih dengan menggunakan rumus berikut:

Di mana:

$$
X^{\prime}=\frac{a .8(x-a)}{b-a}+
$$

$$
\begin{aligned}
& X \quad=\text { Nilai tranformasi } \\
& X=\text { Nilai data ke- } n \\
& 0,8 \quad=\text { Konstanta } \\
& a=\text { Nilai data terkecil } \\
& b=\text { Nilai data terbesar } \\
& 0,1 \quad=\text { Interval }
\end{aligned}
$$

Pelatihan untuk jaringan dengan satu lapisan tersembunyi menggunakan fungsi aktivasi sigmoid biner adalah sebagai berikut:

Langkah 0: Inisialisasi semua bobot dengan bilangan acak kecil.

Langkah 1: Jika kondisi penghentian belum terpenuhi, lakukan langkah 2-9.

Langkah 2: Untuk setiap pasang data pelatihan lakukan langkah 3-8.

Langkah3: Tiap unit masukan menerima sinyal dan meneruskannya ke unit tersembunyi di atasnya.

Langkah 4: Hitungsemua keluaran di unit tersembunyi $z_{j}(j=1,2, \ldots, p)$.

$$
\begin{aligned}
& z_{-} n e t_{j}=v_{j o}+\sum_{i=1}^{n} x_{i} v_{j l} \\
& z_{j}=f\left(z_{-} n e t_{j}\right)=\frac{1}{1+e^{-z_{-} n e t_{j}}}
\end{aligned}
$$

Langkah 5: Hitung semua keluaran jaringan di unit $y_{k}(k=1,2, \ldots, m)$

$$
y_{-} n e t_{k}=w_{k o}+\sum_{j=1}^{p} z_{j} w_{k j}
$$

Langkah 6: Hitung faktor $\delta$ unit keluaran berdasarkan kesalahan di setiap unit keluaran $y_{k}(k=1,2, \ldots, m)$

$$
\delta_{k}=\left(t_{k}-y_{k}\right) f^{\prime}\left(y_{-} n e t_{k}\right)=\left(t_{k}-y_{k}\right) y_{k}(1-
$$
$\left.y_{k}\right)$

Langkah 7: Hitung faktor $\delta$ unit tersembunyi berdasarkan kesalahan di setiap unit tersembunyi $z j(j=1,2, \ldots, p)$

$$
\delta_{-} \text {net }_{j}=\sum_{k=1}^{m} \delta_{k} w_{k j}
$$

Langkah 8: Hitung semua perubahan bobot Langkah 9: Menguji apakah kondisi berhenti sudah terpenuhi. (Muhammad Noor Hasan Siregar, 2015)

Untuk mengembalikan nilai data yang telah ditransformasi sebelumnya, maka dilakukan denormalisasi dengan rumus:

$$
X=\frac{(b-a) *\left(X^{\prime}-0,1\right)}{0,8} \text {. }
$$


Metode Monte Carlo adalah tipe simulasi probabilistik dimana untuk memperoleh penyelesaian masalahnya digunakan metode sampling dari proses random. Dasar simulasi Monte Carlo adalah mengadakan percobaan (eksperimen) pada elemen-elemen probabilistic melalui sampling acak dengan bantuan pembangkitan bilangan random. Metode Monte Carlo dikenal juga dengan istilah Sampling Simulation atau Monte Carlo Sampling Technique. Metode ini menggambarkan kemungkinan penggunaan data sample dalam metode Monte Carlo yang juga sudah diketahui atau diperkirakan distribusinya. Metode ini menggunakan data yang sudah ada (historical data) yang awalnya dipakai untuk keperluan lain.

Langkah-langkah Metode Monte Carlo adalah sebagai berikut:

1. Mendefinisikan distribusi probabilitas dati data masa lalu atau dari distribusi teoritis.

2. Mengkonversikan distribusi kedalam frekuensi kumulatif

3. Melakukan simulasi dengan bilangan acak

4. Menganalisa keluaran simulasi

Rumus Multiplicative RNG :

$\mathbf{Z i}=(\mathbf{a} * \mathbf{Z i}-\mathbf{1}) \operatorname{Mod} M$

$\mathbf{R i}=\mathbf{Z i} / \mathbf{M}$

Dimana :

$$
\begin{array}{ll}
\mathrm{Ri} & =\text { Random Number } \\
\mathrm{Zi} & =\text { Hasil atau Angka Baru } \\
\mathrm{Zi}-1 & =\text { Hasil atau Angka Lama } \\
\mathrm{a} & =\text { Konstanta Bersyarat } \\
\mathrm{c} & =\text { Konstanta Bersyarat } \\
\mathrm{M} & =\text { Angka Modulo }
\end{array}
$$

Rumus untuk $\mathrm{M}$ :

$\mathbf{M}=\mathbf{2}^{\text {bit }-\mathbf{1}}, \mathbf{M}=2^{8-1}=2^{7}=128$

Demam Berdarah Dengue adalah penyakit demam akut, terutama menyerang anak yang disertai dengan manifestasi pendarahan dan bertendensi menimbulkan shock yang menyebabkan kematian serta sering menimbulkan kejadian luar biasa atau wabah. Demam berdarah merupakan penyakit yang disebarkan oleh nyamuk Aedes aegypti yang ditandai dengan demam mendadak, tinggi, dan terus menerus yang berlangsung selama 2 sampai 7 hari disertai dengan tanda pendarahan di kulit, lebam, pendarahan gusi, muntah darah (Suhardiono, 2005).

Selain itu, penyakit demam berdarah juga dapat ditularkan oleh nyamuk Aedes albopictus, di mana kedua jenis nyamuk ini terdapat di seluruh pelosok Indonesia, kecuali di tempat-tempat dengan ketinggian lebih dari 1000 meter di atas permukaan laut.

\section{METODE}

Adapun kerangka kerja dalam penelitian ini sebanyak 6 tahapan yang digambarkan berikut ini:

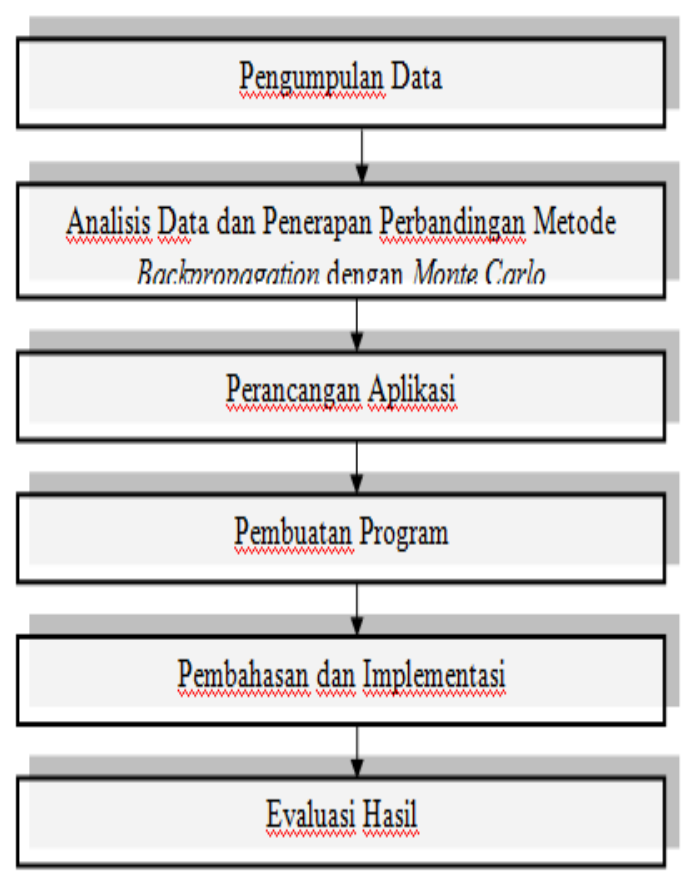

Gambar 1. Metodologi Penelitian

Tahapan diatas dapat dijelaskan sebagai 
berikut :

1. Pengumpulan Data

Melakukan pengumpulan data jumlah penderita demam berdarah tiga tahun terakhir di Dinas Kesehatan Kota Pekanbaru.

2. Analisis Data dan Penerapan Perbandingan Metode

Backpropagation dengan Monte Carlo

3. Perancangan Aplikasi

Membuat rancangan aplikasi sesuai data yang ada berdasarkan tahapan metode yang ditetapkan pada tahapan analisa data.

4. Pembuatan Program

Membuat sebuah aplikasi dengan menerapkan metode Monte Carlo dalam memprediksi jumlah penderita demam berdarah.

5. Pembahasan dan Implementasi

Dilakukan pembahasan yaitu mengolah data secara manual dengan masing-masing metode, dan mengimplementasi data tersebut ke program yang telah dibuat.

6. Evaluasi Hasil

Hasil dari perbandingan prediksi kedua metode kemudian dievaluasi, dan hasil evaluasi ini bisa dijadikan sebagai bahan pengambilan kebijakan bagi pihak terkait

\section{HASIL}

\section{Analisa Metode Backpropogation}

Untuk memprediksi jumlah penderita demam berdarah dengue, diberikan data tiga tahun terakhir, satu periode 12 bulan sebagai data input. Dilakukan pendekatan intuitif, maka yang menjadi target adalah data pada bulan ke-13 setelah periode pertama berakhir sehingga membentuk pola sebanyak 12 pola:

Tabel 1. Pola Data Masukan Prediksi Jumlah Penderita Demam Berdarah

\begin{tabular}{cccccccccccccc}
\hline Pola & $\mathbf{X}_{\mathbf{1}}$ & $\mathbf{X}_{\mathbf{2}}$ & $\mathbf{X}_{\mathbf{3}}$ & $\mathbf{X}_{\mathbf{4}}$ & $\mathbf{X}_{\mathbf{5}}$ & $\mathbf{X}_{\mathbf{6}}$ & $\mathbf{X}_{\mathbf{7}}$ & $\mathbf{X}_{\mathbf{8}}$ & $\mathbf{X}_{\mathbf{9}}$ & $\mathbf{X}_{\mathbf{1 0}}$ & $\mathbf{X}_{\mathbf{1 1}}$ & $\mathbf{X}_{\mathbf{1 2}}$ & Target \\
\hline Pola 1 & 17 & 20 & 59 & 21 & 39 & 36 & 38 & 56 & 30 & 60 & 30 & 20 & 13 \\
\hline Pola 2 & 20 & 59 & 21 & 39 & 36 & 38 & 56 & 30 & 60 & 30 & 20 & 13 & 12 \\
\hline Pola 3 & 59 & 21 & 39 & 36 & 38 & 56 & 30 & 60 & 30 & 20 & 13 & 12 & 8 \\
\hline Pola 4 & 21 & 39 & 36 & 38 & 56 & 30 & 60 & 30 & 20 & 13 & 12 & 8 & 5 \\
\hline Pola 5 & 39 & 36 & 38 & 56 & 30 & 60 & 30 & 20 & 13 & 12 & 8 & 5 & 8 \\
\hline Pola 6 & 36 & 38 & 56 & 30 & 60 & 30 & 20 & 13 & 12 & 8 & 5 & 8 & 6 \\
\hline Pola 7 & 38 & 56 & 30 & 60 & 30 & 20 & 13 & 12 & 8 & 5 & 8 & 6 & 4 \\
\hline Pola 8 & 56 & 30 & 60 & 30 & 20 & 13 & 12 & 8 & 5 & 8 & 6 & 4 & 2 \\
\hline Pola 9 & 30 & 60 & 30 & 20 & 13 & 12 & 8 & 5 & 8 & 6 & 4 & 2 & 4 \\
\hline Pola 10 & 60 & 30 & 20 & 13 & 12 & 8 & 5 & 8 & 6 & 4 & 2 & 4 & 8 \\
\hline Pola 11 & 30 & 20 & 13 & 12 & 8 & 5 & 8 & 6 & 4 & 2 & 4 & 8 & 22 \\
\hline Pola 12 & 20 & 13 & 12 & 8 & 5 & 8 & 6 & 4 & 2 & 4 & 8 & 22 & 21 \\
\hline
\end{tabular}

Dalam penelitian ini, arsitektur Jaringan Syaraf Tiruan yang digunakan berlapis banyak dengan metode Backpropagation:

1. Lapisan input terdiri dari 12 masukan: dimana $X_{1}=$ Januari, $X_{2}=$ Februari, $X_{3}=$
Maret, $X_{4}=$ April, $X_{5}=$ Mei, $X_{6}=$ Juni, $X_{7}=$ Juli, $X_{8}=$ Agustus, $X_{9}=$ September, $X_{10}=$ Oktober, $\quad X_{11}=$ November, $\quad X_{12}=$ Desember.

2. Lapisan hidden dengan jumlah yang ditentukan oleh peneliti. 
3. Lapisan output dengan 1 lapisan yaitu prediksi jumlah penderita demam berdarah.

Arsitektur jaringan yang terbentuk adalah 12-6-1 dimana:

$$
X \quad=\operatorname{masukan}(\text { input) }
$$

$V=$ bobot pada lapisan tersembunyi (hidden layer)

$W=$ bobot pada lapisan keluaran (output layer)

$Y \quad=$ keluaran (ouput)

$B=$ Bias pada hidden layer dan ouputlayer

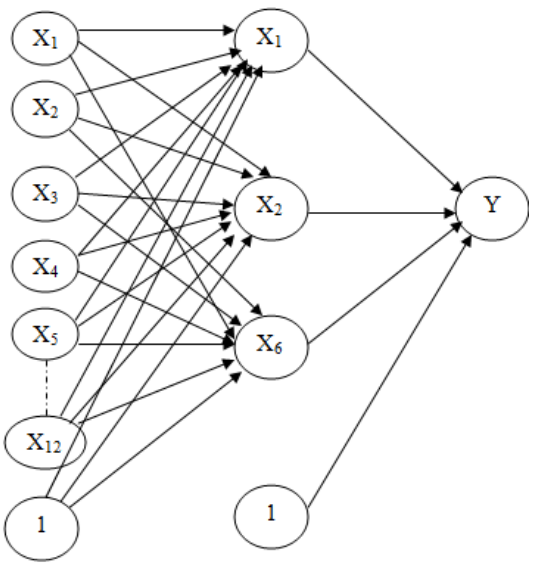

Gambar 2. Arsitektur Jaringan

Backpropagation dari Prediksi Jumlah

Penderita Demam Berdarah

\section{Normalisasi Data}

Agar Jaringan Syaraf Tiruan dapat mengenali pola, maka perlu dilatih dengan data yang latih yang terlebih dahulu dinormalisasi atau ditransformasikan ke dalam angka yang jauh lebih kecil. Dalam Backpropagation untuk mentranformasi data menggunakan fungsi sigmoid biner dengan rentang nilai 0 hingga 1. Akan sangat lebih baik lagi bila nilai tersebut memiliki interval jauh lebih kecil yaitu 0,1 hingga 0,9. Untuk mentranformasi data latih dapat menggunakan formula 2.7.

Formula tersebut dapat disimulasikan pada data latih dan data uji yang ada di Tabel 4.2 dan Tabel 4.3, dimana data $a=2$; $b=60 ; x=17$, maka:

$$
X^{\prime}=\frac{0.8(60-2)}{60-2}+=0,3069
$$

Hal yang sama juga dilakukan pada data latih, berikut transformasi data latih:

\begin{tabular}{|c|c|c|c|c|c|c|c|c|c|c|c|c|}
\hline Pola & $\mathbf{X}_{2}$ & $\mathbf{X}_{3}$ & $\mathbf{X}_{4}$ & $\mathbf{X}_{5}$ & $X_{6}$ & $\mathbf{X}_{7}$ & $\mathbf{X}_{8}$ & $X_{9}$ & $\mathbf{X}_{10}$ & $\mathbf{X}_{11}$ & $\mathbf{X}_{12}$ & Target \\
\hline \multirow{2}{*}{1} & & & 0.362 & 0.610 & 0.569 & 0.596 & & & & 0.4862 & 0.348 & 0.2517 \\
\hline & 0.30690 .3483 & 0.8862 & 1 & 3 & 0 & 6 & 0.8448 & 0.4862 & 0.9000 & & 3 & \\
\hline \multirow{2}{*}{2} & & & 0.610 & 0.569 & 0.596 & 0.844 & & & & 0.3483 & 0.251 & 0.2379 \\
\hline & 0.34830 .8862 & 0.3621 & 3 & 0 & 6 & 8 & 0.4862 & 0.9000 & 0.4862 & & 7 & \\
\hline \multirow{2}{*}{3} & & & 0.569 & 0.596 & 0.844 & 0.486 & & & & 0.2517 & 0.237 & 0.1828 \\
\hline & 0.88620 .3621 & 0.6103 & 0 & 6 & 8 & 2 & 0.9000 & 0.48 & 0.3483 & & 9 & \\
\hline & & & 0.596 & 0.844 & 0.486 & 0.900 & & & & 0.2379 & 0.182 & 0.1414 \\
\hline & 0.36210 .6103 & 0.5690 & 6 & 8 & 2 & 0 & 0.4862 & 0.3483 & 0.2517 & & 8 & \\
\hline & & & 0.844 & 0.486 & 0.900 & 0.486 & & & & 0.1828 & 0.141 & 0.1828 \\
\hline & 0.61030 .5690 & 0.5966 & 8 & 2 & 0 & 2 & 0.3483 & 0.2517 & 0.2379 & & 4 & \\
\hline 6 & 0.56900 .5966 & 0.8448 & 0.486 & 0.900 & 0.486 & 0.348 & 0.2517 & 0.2379 & 0.1828 & 0.1414 & 0.182 & 0.1552 \\
\hline
\end{tabular}

Tabel 2.Data Latih Jumlah Penderita Demam Berdarah 
RABIT : Jurnal Teknologi dan Sistem Informasi Univrab

Volume 2 No. 2 | Juli 2017 : 72-82

\begin{tabular}{|c|c|c|c|c|c|c|c|c|c|c|}
\hline & & & 2 & 0 & 2 & 3 & & & 8 & \\
\hline \multirow{2}{*}{7} & & & 0.900 & 0.486 & 0.348 & 0.251 & & 0.1828 & 0.155 & 0.1276 \\
\hline & 0.59660 .8448 & 0.4862 & 0 & 2 & 3 & 7 & $\begin{array}{llll}0.2379 & 0.1828 & 0.1414\end{array}$ & & 2 & \\
\hline \multirow{2}{*}{8} & & & 0.486 & 0.348 & 0.251 & 0.237 & & 0.1552 & 0.127 & 0.1000 \\
\hline & 0.84480 .4862 & 0.9000 & 2 & 3 & 7 & 9 & $\begin{array}{llll}0.1828 & 0.1414 & 0.1828\end{array}$ & & 6 & \\
\hline \multirow{2}{*}{9} & & & 0.348 & 0.251 & 0.237 & 0.182 & & 0.1276 & 0.100 & 0.1276 \\
\hline & 0.48620 .9000 & 0.4862 & 3 & 7 & 9 & 8 & $\begin{array}{llll}0.1414 & 0.1828 & 0.1552\end{array}$ & & 0 & \\
\hline \multirow{2}{*}{10} & & & 0.251 & 0.237 & 0.182 & 0.141 & & 0.1000 & 0.127 & 0.1828 \\
\hline & 0.90000 .4862 & 0.3483 & 7 & 9 & 8 & 4 & $\begin{array}{llll}0.1828 & 0.1552 & 0.1276 \\
\end{array}$ & & 6 & \\
\hline \multirow{2}{*}{11} & & & 0.237 & 0.182 & 0.141 & 0.182 & & 0.1276 & 0.182 & 0.3759 \\
\hline & 0.48620 .3483 & 0.2517 & 9 & 8 & 4 & 8 & $\begin{array}{llll}0.1552 & 0.1276 & 0.1000\end{array}$ & & 8 & \\
\hline \multirow{2}{*}{12} & & & 0.182 & 0.141 & 0.182 & 0.155 & & 0.1828 & 0.375 & 0.3621 \\
\hline & 0.34830 .2517 & 0.2379 & 8 & 4 & 8 & 2 & $\begin{array}{llll}0.1276 & 0.1000 & 0.1276\end{array}$ & & 9 & \\
\hline
\end{tabular}

\section{Pelatihan dan Pengujian dengan}

\section{Backpropagation}

Pelatihan Jaringan Syaraf Tiruan dilakukan pada arsitektur jaringan yaitu arsitektur 12-6-1. Pelatihan dilakukan dengan menggunakan perintah-perintah Matlab yang diketikkan pada Command Window. Dari pelatihan dan pengujian yang dilakukan, maka didpat hasil seperti tabel dibawah ini:

Tabel 3. Prediksi Jumlah Penderita

Demam Berdarah pada Tahun 2015

\begin{tabular}{cclc}
\hline $\begin{array}{c}\text { Data } \\
\text { Ke }\end{array}$ & $\begin{array}{c}\boldsymbol{Y} \\
\text { Aktual }\end{array}$ & Bulan & $\begin{array}{c}\text { Jumlah } \\
\text { DBD }\end{array}$ \\
\hline 1 & 0.2512 & Januari & 13 \\
\hline 2 & 0.1900 & Februari & 9 \\
\hline 3 & 0.1793 & Maret & 8 \\
\hline 4 & 0.1259 & April & 4 \\
\hline 5 & 0.1287 & Mei & 4 \\
\hline 6 & 0.3501 & Juni & 20 \\
\hline 7 & 0.2413 & Juli & 12 \\
\hline 8 & 0.1464 & Agustus & 5 \\
\hline 9 & 0.1518 & September & 6 \\
\hline 10 & 0.1031 & Oktober & 2 \\
\hline 11 & 0.1844 & November & 8 \\
\hline 12 & 0.3746 & Desember & 22 \\
\hline
\end{tabular}

\section{Analisa Metode Monte Carlo}

Adapun langkah-langkah metode Monte Carlo sebagai berikut:

1. Menentukan distribusi densitas dari data 3 tahun terakhir.

Contoh untuk tahu 2012: 37/67*100

$=55.223881$, untuk mencari nilai berikutnya dengan cara yang sama. Berikut hasil yang didapat.

Tabel 4. Distribusi Densitas

\begin{tabular}{ccccc}
\hline Bulan & $\mathbf{2 0 1 2}$ & $\mathbf{2 0 1 3}$ & $\mathbf{2 0 1 4}$ & Jumlah \\
\hline 1 & 55.22 & 25.37 & 19.40 & 100 \\
\hline 2 & 57.33 & 26.66 & 16.00 & 100 \\
\hline 3 & 26.37 & 64.83 & 8.79 & 100 \\
\hline 4 & 21.21 & 63.64 & 15.15 & 100 \\
\hline 5 & 17.54 & 68.42 & 14.03 & 100 \\
\hline 6 & 6.67 & 80 & 13.33 & 100 \\
\hline 7 & 16 & 76 & 8 & 100 \\
\hline 8 & 6.45 & 90.32 & 3.22 & 100 \\
\hline 9 & 12.82 & 76.92 & 10.25 & 100 \\
\hline 10 & 23.60 & 67.41 & 8.99 & 100 \\
\hline 11 & 25.71 & 42.85 & 33.33 & 100 \\
\hline 12 & 34.92 & 31.74 & 33.33 & 100
\end{tabular}

2. Selanjutnya mencari nilai distribusi frekuensi kumulatif dengan cara 
membagikan nilai dengan 100 . Contoh :

$55.224 / 100=0.55$,

Tabel 5. Distribusi Frekuensi Kumulatif

\begin{tabular}{ccc}
\hline $\mathbf{2 0 1 2}$ & $\mathbf{2 0 1 3}$ & $\mathbf{2 0 1 4}$ \\
\hline 0.55 & 0.25 & 0.20 \\
\hline 0.57 & 0.27 & 0.16 \\
\hline 0.26 & 0.65 & 0.09 \\
\hline 0.21 & 0.64 & 0.15 \\
\hline 0.18 & 0.68 & 0.14 \\
\hline 0.07 & 0.80 & 0.13 \\
\hline 0.16 & 0.76 & 0.08 \\
\hline 0.07 & 0.90 & 0.03 \\
\hline 0.13 & 0.77 & 0.10 \\
\hline 0.24 & 0.67 & 0.09 \\
\hline 0.26 & 0.43 & 0.31 \\
\hline 0.35 & 0.32 & 0.33 \\
\hline
\end{tabular}

Selanjutnya data pada tahun 2012 datanya tetap dan untuk tahun 2013 ditambahkan dengan 0.25. Contoh: $0.55+0.25=0.80$ dan untuk mendapatkan nilai ditahun 2014 dilakukan dengan cara yang sama yaitu menambahkan data pada tahun 2014 dengan hasil pada tahun 2013. Contoh: $0.20+0.80=1.00$. cara yang sama untuk mencari data berikutnya. Dibawah ini merupakan hasil lengkapnya.

Tabel 6. Jumlah Distribusi Frekuensi

Kumulatif Tahun 2012-2015

\begin{tabular}{llll}
\hline No & & & $\mathbf{2 0 1}$ \\
& $\mathbf{2 0 1 2}$ & $\mathbf{2 0 1 3}$ & $\mathbf{4}$ \\
\hline 1 & 0.55 & 0.80 & 1.00 \\
\hline 2 & 0.57 & 0.84 & 1.00 \\
\hline 3 & 0.26 & 0.91 & 1.00 \\
\hline 4 & 0.21 & 0.85 & 1.00 \\
\hline 5 & 0.18 & 0.86 & 1.00 \\
\hline 6 & 0.07 & 0.87 & 1.00 \\
\hline 7 & 0.16 & 0.92 & 1.00 \\
\hline 8 & 0.07 & 0.97 & 1.00 \\
\hline
\end{tabular}

\begin{tabular}{cccc}
\hline 9 & 0.13 & 0.90 & 1.00 \\
\hline 10 & 0.24 & 0.91 & 1.00 \\
\hline 11 & 0.26 & 0.69 & 1.00 \\
\hline 12 & 0.35 & 0.67 & 1.00 \\
\hline
\end{tabular}

3. Selanjutnya membuat range dari cumulatif densitas frekuensi yang didapat

Tabel 7. Range untuk Bulan Januari

\begin{tabular}{ccccc}
\hline Bulan & Tahun & $\begin{array}{c}\text { Distribusi } \\
\text { Densitas }\end{array}$ & CDF & Ri \\
\hline \multirow{4}{*}{ Januari } & 2012 & & & $0-$ \\
\cline { 2 - 5 } & 2013 & 25.373 & 0.8 & $0.56-$ \\
& & & & 0.80 \\
\cline { 2 - 5 } & 2014 & 19.403 & 1 & 0.81 \\
& & & & -1 \\
\hline
\end{tabular}

4. Mencari bilangan random dengan rumus $\mathrm{Zi}=(\mathrm{a} * \mathrm{Zi}-1) \operatorname{Mod} 128$

$$
\begin{aligned}
& \mathrm{Z} 0=12357 \\
& \mathrm{a}=25 \\
& \begin{aligned}
\mathrm{M} & =128 \\
\mathrm{Z} 1 & =(25 * \mathrm{Zi}-1) \operatorname{Mod} 128 \\
& =(25 * \mathrm{Z} 0) \operatorname{Mod} 128 \\
& =(25 * 12357) \text { Mod } 128 \\
& =308924 \operatorname{Mod} 128 \\
& =2413+0,4688
\end{aligned}
\end{aligned}
$$

Tabel 8. Bilangan Random yang Terbentuk

\begin{tabular}{ccccc}
\hline $\mathrm{Zi}$ & $\begin{array}{c}\text { (a*Zi- } \\
1)\end{array}$ & $\begin{array}{l}\text { (a* } \mathrm{Zi}- \\
\text { 1) Mod } \\
\mathrm{M}\end{array}$ & $\mathrm{Ri}$ & $\mathrm{Zi}=$ \\
& & & & $\mathrm{Ri} * \mathrm{M}$ \\
$\mathrm{Z} 1$ & 308924 & 2413.46 & 0.468 & 60.006 \\
\hline $\mathrm{Z} 2$ & 1499.16 & 11.7122 & 0.712 & 91.161 \\
\hline
\end{tabular}


RABIT : Jurnal Teknologi dan Sistem Informasi Univrab

Volume 2 No. 2 | Juli 2017 : 72-82

\begin{tabular}{rcccc}
\hline Z3 & 2278.04 & 17.7972 & 0.797 & 102.04 \\
\hline Z4 & 2550.04 & 19.9222 & 0.922 & 118.04 \\
\hline$\ldots$ & $\ldots$ & $\ldots$ & $\ldots$ & $\ldots$ \\
\hline & & & & \\
\hline & & & & \\
\hline$\ldots$ & $\ldots$ & $\ldots$ & $\ldots$ & $\ldots$ \\
\hline Z92 & 2550.04 & 19.9222 & 0.922 & 118.04 \\
\hline Z93 & 2950.04 & 23.0472 & 0.047 & 6.041 \\
\hline Z94 & 150.04 & 1.1722 & 0.172 & 22.041 \\
\hline Z95 & 550.04 & 4.2972 & 0.297 & 38.041 \\
\hline Z96 & 950.04 & 7.4222 & 0.422 & 54.041 \\
\hline Z97 & 1350.04 & 10.5472 & 0.547 & 70.041 \\
\hline Z98 & 1750.04 & 13.6722 & 0.672 & 86.041 \\
\hline Z99 & 2150.04 & 16.7972 & 0.797 & 102.04 \\
\hline Z100 & 2550.04 & 19.9222 & 0.922 & 118.04 \\
\hline
\end{tabular}

\section{Standar Deviasi}

Agar hasil prediksi antara metode Backpropagation dan Monte Carlo bagus, diuji dengan standar deviasi

1. Standar Deviasi untuk metode

Backpropagat:-...

$$
\begin{aligned}
& \quad s=\sqrt{\frac{\sum_{i=1}^{n}\left(x_{i}-\bar{x}\right)^{2}}{n-1}} \\
& \mathrm{n}=12 \\
& \mathrm{Xi}=13,9,8,4,4,20,12,5,6,2,8,22 \\
& \mathrm{X} \text { rata }=\underline{(13+9+8+. .22)}=\underline{113}=
\end{aligned}
$$

9.411

$$
\begin{aligned}
& \mathrm{S}=\sqrt{\frac{(13-9,4)^{2}+(9-9,4)^{2}+\cdots-(22-9,4)^{2}}{12-1}} \\
& S=6.3058 \%
\end{aligned}
$$

2. Standar Deviasi untuk metode Monte Carlo

$$
\begin{aligned}
& n=12 \\
& X i=142 ., 91,91,165,32,128,81, \ldots
\end{aligned}
$$

149,91

$$
\text { Xrata }=\underline{(142+92+91 \ldots \ldots+91)}=
$$

$\underline{1203}=100,25$

$$
\mathrm{S}=\sqrt{\frac{25260,25}{11}}=
$$

$\mathrm{S}=47,9306 \%$

\section{Implementasi Metode Backpropagation}

Pada tahap implementasi algoritma Backpropagation dengan Matlab, peneliti menggunakan Matlab 6.1. Versi ini memang versi lama yang masih mendukung untuk pengujian berbasis command linekarena skripnya yang sangat sederhana.

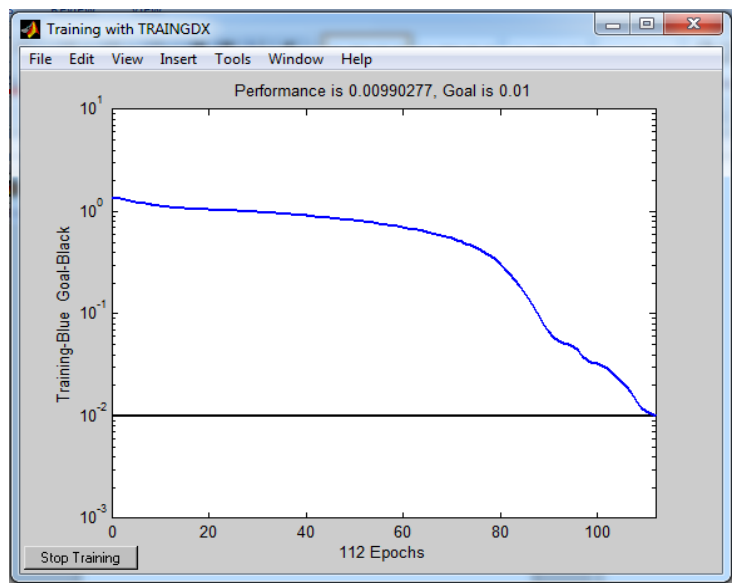

Gambar 3 : Pelatihan Mencapai Goal pada Epoch Ke 112 pada Arsitektur 12-6-1

Setelah pelatihan telah mencapai goal yang ditetapkan, maka dilakukan pengujian pada data latih terhadap target dan errornya dengan menggunakan perintah berikut ini:

$>>$ an $=\operatorname{sim}($ net,pn);

$>>\mathrm{a}=\operatorname{poststd}(\mathrm{an}, \mathrm{meant}, \mathrm{stdt}) ;$

$>>\mathrm{H}=\left[(1: \operatorname{size}(\mathrm{P}, 2))^{\prime} \mathrm{T}^{\prime} \mathrm{a}^{\prime}\left(\mathrm{T}^{\prime}-\mathrm{a}^{\prime}\right)\right]$;

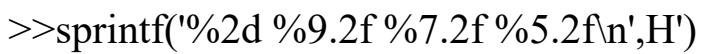

$>>[\mathrm{m} 1, \mathrm{a} 1, \mathrm{r} 1]=\operatorname{postreg}(\mathrm{a}, \mathrm{T})$. 


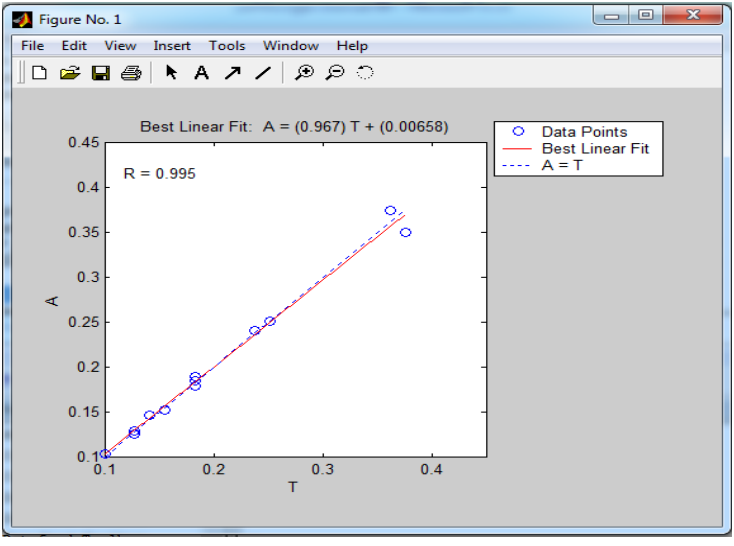

Gambar 4. Kesesuaian Keluaran

Terhadap Target pada Pengujian Arsitektur

\section{2-6-1}

Berdasarkan hasil prediksi jumlah demam berdarah untuk tahun 2015, Jaringan Syaraf Tiruan dengan metode Backpropagationdengan arsitektur 12-6-1 dapat digunakan untuk memprediksi jumlah penderita demam berdarah di Kota Pekanbaru karena memiliki tingkat akurasi $100 \%$ dan MSE yang lebih kecil,

\section{Implementasi Monte Carlo}

Pada metode Monte Carlo implementasinya dengan membuat sebuah aplikasi dengan menggunakan bahasa pemrograman PHP.

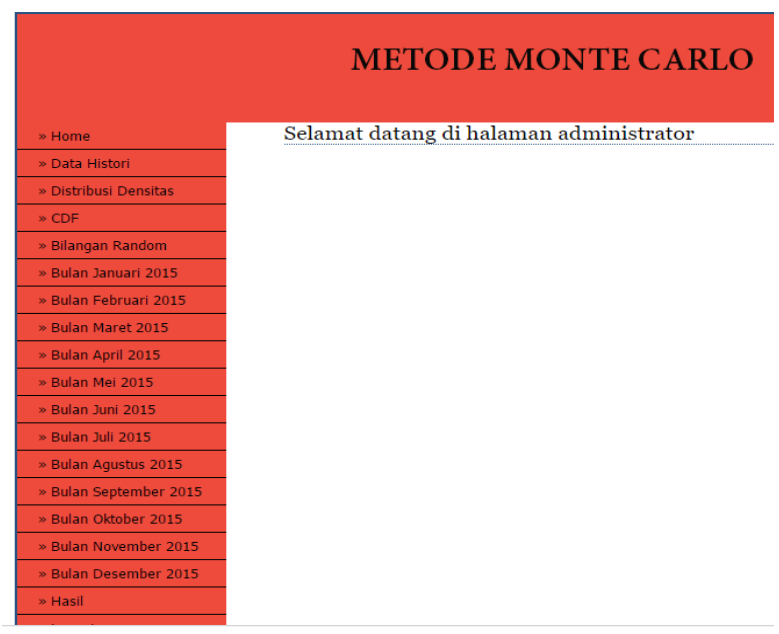

Gambar 5. Halaman Administrator Aplikasi Metode Monte Carlo
Pada halaman ini semua langkah metode Monte Carlo dilakukan. Mulai dari menentukan distribusi densitas sampai hasil prediksi jumlah penderita demam berdarah. Berikut hasil prediksi penderita demam berdarah oleh metode Monte Carlo

\begin{tabular}{|l|c|c|c|}
\hline NO & BULAN & DATA ASU & PREDIKSI \\
\hline 1 & Januari & 18 & 142 \\
\hline 2 & Februari & 14 & 91 \\
\hline 3 & Maret & 1 & 91 \\
\hline 4 & April & 22 & 165 \\
\hline 5 & Mei & 24 & 32 \\
\hline 6 & Juni & 6 & 128 \\
\hline 7 & Juli & 3 & 81 \\
\hline 8 & Agustus & 42 & 155 \\
\hline 9 & September & 28 & 53 \\
\hline 10 & Oktober & 37 & 25 \\
\hline 11 & November & 40 & 149 \\
\hline 12 & Desember & 37 & 91 \\
\hline
\end{tabular}

Gambar 6. Perbandingan Hasil Prediksi dengan Data Asli

Langkah terakhir dari pencarian prediksi dengan masing-masing metode adalah membuat rekap atau tabel perbandingan dari kedua metode tersebut, dibawah ini bisa dilihat perbandingan hasil prediksi jumlah penderita demam berdarah dengan kedua metode.

Tabel 9. Perbandingan Hasil Prediksi Kedua Metode dengan Data Aktual Tahun 2015

\begin{tabular}{|c|l|c|c|c|}
\hline \multirow{2}{*}{ No. } & \multirow{2}{*}{ Bulan } & $\begin{array}{c}\text { Monte } \\
\text { Carlo }\end{array}$ & Backpropagation & \multirow{2}{*}{$\begin{array}{c}\text { Data } \\
\text { Aktual }\end{array}$} \\
\cline { 3 - 4 } & & Prediksi & Prediksi & \\
\hline 1 & Januari & 142 & 20 & 18 \\
\hline 2 & Februari & 91 & 3 & 14 \\
\hline 3 & Maret & 91 & 25 & 1 \\
\hline 4 & April & 165 & 2 & 22 \\
\hline 5 & Mei & 32 & 29 & 24 \\
\hline 6 & Juni & 128 & 40 & 6 \\
\hline 7 & Juli & 81 & 10 & 3 \\
\hline 8 & Agustus & 155 & 21 & 42 \\
\hline 9 & September & 53 & 6 & 28 \\
\hline 10 & Oktober & 25 & 42 & 37 \\
\hline 11 & November & 149 & 37 & 40 \\
\hline 12 & Desember & 91 & 37 & 37 \\
\hline
\end{tabular}


Dari tabel diatas terlihat hasil prediksi jumlah penderita demam berdarah dengue setiap bulannya, dengan Metode Backpropagation dan Monte Carlo. Setelah dilakukan perbandingan, didapat hasil Metode Backpropagation lebih mendekati data actual jumlah penderita demam berdarah dengue. Sehingga Metode Backpropagation dalam kasus ini lebih akurat dalam memprediksi jumlah penderita demam berdarah dengue di Kota Pekanbaru Tahun 2015.

\section{KESIMPULAN}

Dari penelitian ini dapat ditarik kesimpulan:

1. Dari hasil perbandingan kedua metode, didapatkan hasil bahwa standar deviasi untuk metode Backpropagation sebesar $6.30 \%$, sedang untuk metode Monte Carlo sebesar 47,93\%.

2. Karena memiliki standar deviasi yang rendah metode Backpropagation lebih baik dalam memprediksi jumlah penderita penyakit demam berdarah dengue.

3. Semakin kecil standar deviasi semakin akurat/optimal dalam hal memprediksi.

\section{DAFTAR PUSTAKA}

[1]. Anwar, Badrul. "Penerapan Jaringan Syaraf Tiruan Backpropagation dalam Memprediksi Tingkat Suku Bunga Bank". Journal
SAINTIKOM,

10(2):111-121.2011

[2].Dinas Kesehatan Kota Pekanbaru, Data Jumlah Penderita Demam Berdarah Dengue, Data diambil pada Bulan November 2016.

[3]. Lamhot P, Manalu,"Menghitung Kebutuhan Pengeting Gabah di Kecamatan Ciomas Bogor dengan Metode Monte Carlo." Jurnal Sains dan Teknologi Indonesia Vol.11 No.3, Hal 151-156. Desember 2009

[4]. Nurhayati dan Fitri Adi Iskandarianto, "Penerapan Metode Back Propagation Neural Network pada Pendeteksian Kelainan Otak Ischemic CerebralInfraction dengan Bahasa Pemrograman Delphi." Jurnal Fisika dan Aplikasinya. 6 (1). 1-6.2010

[5]. Raditya Lucky Riswanto, Sutikno, dan Indriyati, "Aplikasi Prediksi Jumlah Penderita Penyakit Demam Berdarah Dengue di Kota Semarang Menggunakan Jaringan Syaraf Tiruan Backrpopagation”. Jurnal Masyarakat Informatika, Volume 5, Nomor 10, ISSN 2086-4930. 2012 